\title{
Em busca da mentira: historiadores contra a falsificação do Holocausto
}

In Search of Lies: Historians Against Holocaust Forgery

Eduardo Wright Cardoso ${ }^{*}, *$

\section{Resumo}

A história nunca deixou de se confrontar com a mentira. Como argumenta Anthony Grafton, a falsificação é uma contraparte da busca pela verdade, podendo, inclusive, estimular procedimentos de atestação e verificação do saber histórico. Este trabalho investiga dois empreendimentos contemporâneos de desmascaramento da mentira, levados a cabo por historiadores profissionais. Pierre Vidal-Naquet, em "Os assassinos da memória”, e Deborah E. Lipstadt, em "Negação", opuseram-se ao negacionismo do Holocausto e, nesse embate, explicitaram alguns dos pressupostos básicos da operação histórica. No artigo, procuro discutir categorias centrais que orientam o ofício historiográfico, como verdade, prova e autópsia, reivindicadas como ferramentas fundamentais no combate às práticas negacionistas. As iniciativas de Vidal-Naquet e Lipstadt permitem compreender não somente os recursos disponíveis e as possibilidades oferecidas aos historiadores, mas também as limitações institucionais na contínua e premente tarefa de identificar e combater a mentira. Palavras-chave: Negacionismo; Prova; Autópsia; Falsificação.

\section{ABstract}

History has always been confronted with lies. As Anthony Grafton argues, forgery is a counterpart to the search for the truth, and can even stimulate procedures for attesting and verifying historical knowledge. This paper investigates two contemporary attempts carried out by professional historians to uncover lies. Pierre Vidal-Naquet, in "The Killers of Memory", and Deborah E. Lipstadt, in "Denial", have opposed Holocaust denialism and, in this struggle against lies, have made explicit some of the basic assumptions of the historical operation. I seek to discuss key notions that guide the historical craft, such as truth, proof, and autopsy; claimed as fundamental tools in the fight against the denialist practices. The initiatives of Vidal-Naquet and Lipstadt allow us to understand not only the resources available and the possibilities offered to historians but also the institutional limitations in the continuous and pressing task of identifying and confronting lies.

Keywords: Denialism; Proof; Autopsia; Forgery.

\footnotetext{
* Pontifícia Universidade Católica do Rio de Janeiro (PUC-RJ), Rio de Janeiro, RJ, Brasil. edu.wright@ gmail.com <https://orcid.org/0000-0002-6932-1000>

** O presente trabalho foi realizado com apoio da Coordenação de Aperfeiçoamento de Pessoal de Nível Superior - Brasil (CAPES) - Código de Financiamento 001. Gostaria também de agradecer à PUC-Rio pela "Bolsa de incentivo à produtividade em ensino e pesquisa aos novos professores".
} 
A multiplicação de termos que procuram registrar e apreender as primeiras décadas do século XXI parece indiciar uma época marcada por mudanças no que diz respeito ao valor da verdade. Assim, noções como pseudociência, pós-verdade, fatos alternativos, entre tantas outras, tornaram-se parte do vocabulário cotidiano e do debate público. Como constatou também Valdei Araujo, expressões como fake-news e negacionismo [denialism] cresceram de modo acelerado nos últimos anos (Araujo; Valim; Avelar, 2020). Multiplicaram-se igualmente as obras que pretendem compreender o fenômeno e a conjuntura atual. Em livro de 2018, por exemplo, a crítica literária norte-americana Michiko Kakutani não hesita em afirmar que nos encontramos em um momento marcado por uma "epidemia de notícias falsas" ou, como sugere o título de seu livro, pela "morte da verdade" (Kakutami, 2018). ${ }^{1}$ Se o diagnóstico é válido, isto é, se a verdade já não é capaz de subsistir aos ataques constantes, como os conhecimentos que se organizam em torno dela podem sobreviver? De modo mais específico, como o saber histórico pode enfrentar essa hostilidade em relação à verdade?

Um breve exercício de historicização, por outro lado, permite sugerir que a disseminação de discursos mentirosos e falsificações nada possui de novo. Assim, não parece ser excessivo lembrar que a identificação de uma época perpassada por mentiras não é inédita. Ainda durante a II Guerra Mundial, o filósofo Alexandre Koyré, em um artigo inicialmente denominado "Reflexões sobre a mentira", afirmava de modo enfático: "Nunca se mentiu tanto quanto nos dias de hoje. E nunca se mentiu de maneira tão despudorada, sistemática e constante" (Koyré, 2015, p. 72). O diagnóstico, elaborado em 1943, não difere muito daquele construído por George Orwell que, igualmente, constatava um período de descrença generalizada. A diferença é que o escritor britânico identificava essa situação já na década anterior, isto é, no contexto da Guerra Civil Espanhola. Nos seus termos: "Estou disposto a aceitar que a história quase sempre é inexata e tendenciosa, mas o que distingue a nossa época é o abandono da ideia de que é possível escrever a história com veracidade" (Orwell, 2020, p. 101). Enquanto Orwell antecipa a dificuldade que os historiadores e as historiadoras encontrarão para realizar seus trabalhos, Hannah Arendt, em textos produzidos entre as décadas de 1950 e 1970, oferece, por sua vez, uma descrição semelhante. De acordo com a teórica da política, seria possível falar em uma hostilização da verdade e, inclusive, no nascimento de um 
tipo novo de falsificação, a "mentira moderna", cujo pressuposto é não apenas a ocultação, mas a destruição da verdade (Arendt, 2016, p. 312).

Como posicionar-se diante dessas dúvidas e contestações? Como a prática histórica poderia responder aos ataques em relação à verdade? Antecipo, desde já, que não disponho de respostas definitivas, ainda que este artigo tenha sido motivado por inquietações semelhantes a essas. Como uma tentativa de aproximação, portanto, a essas indagações, gostaria de tentar elaborar um breve mapeamento de algumas reflexões contemporâneas produzidas no âmbito da escrita da história acadêmica e pública, que buscaram identificar e combater a mentira e a falsificação sobre os eventos relacionados ao Holocausto, ou seja, enfrentaram "práticas negacionistas". De acordo com Luís Edmundo Moraes, o termo negacionismo é impreciso, pois tanto abarca fenômenos e conteúdos variados, quanto pode ser compreendido a partir da constituição de uma prática (Moraes, 2011, p. 3-4). Enfatizando o ponto de vista procedural, Moraes defende que o negacionismo pode ser caracterizado como uma "fraude em um duplo sentido", ou seja, constitui uma "historiografia falsifica$d a$ " que reivindica "o caráter de escrito historiográfico sem sê-lo", e constrói um "passado falsificado", "reivindicando o caráter de proposições verificáveis sem sê-lo" (Moraes, 2011, p. 15). Como prática fraudulenta, o negacionismo tanto recusa uma identificação com o revisionismo, quanto permite uma aproximação com as leituras sobre a falsificação desenvolvidas por Anthony Grafton. O historiador norte-americano sugere que a falsificação é um tipo de crime que, como tal, pode ser investigado a partir dos seus motivos, dos seus meios e das suas oportunidades (Grafton, 1990, p. 37). Por isso, também, Grafton não hesita em afirmar, sem reduzi-las uma à outra, que a falsificação está ligada à mentira, ou melhor, que o falsário mente (Grafton, 1990, p. 126).

\section{HistóRIA E NEGACIONISMO: UMA “ANATOMIA DA MENTIRA”}

Creio ser válido recuperar aqui um empreendimento simultaneamente teórico e prático de análise da falsificação, que permite apresentar as ferramentas da história no combate à mentira. Trata-se do conjunto de textos escritos por Pierre Vidal-Naquet e reunidos, em 1987, sob o título "Os assassinos da memória”. Francês de origem judaica, o consagrado historiador da Antiguidade não deixou de se dedicar às questões mais urgentes do presente e, nesse 
sentido, poderia ser classificado como um "historiador público" (Hartog, 2007). Frente à ascensão das práticas revisionistas e negacionistas, que considera análogas, Vidal-Naquet elaborou o que poderia ser classificado, segundo seus termos, como uma "anatomia da mentira" (Vidal-Naquet, 1988, p. 11). ${ }^{2}$ $\mathrm{Na}$ obra, entre os procedimentos e as possibilidades do conhecimento histórico, o historiador não deixa de reconhecer os limites do empreendimento: " $\mathrm{Na}$ verdade, não se refuta um sistema fechado, uma mentira total que não se situa na ordem do refutável, pois aí a conclusão precede as provas" (Vidal-Naquet, 1988, pp. 122-123).

A despeito da ressalva, Vidal-Naquet não hesita em desenvolver uma historicização da prática negacionista que inclui a tentativa de definir suas origens, alguns de seus métodos e de suas condutas mais usuais. Logo na abertura da obra, o historiador defende o valor supremo da verdade, que assegura ser indestrutível (Vidal-Naquet, 1988, p. 9). No entanto, não deixa de reconhecer, tal como alguns de seus predecessores mencionados acima, que o momento contemporâneo era perigoso, na medida em que a verdade era alvo de ataques. Segundo suas palavras: "Esse termo [a verdade], outrora sério, tende atualmente a se dissolver" (Vidal-Naquet, 1988, p. 10). A percepção remete ao diagnóstico de Arendt: à diferença do mundo antigo, no contexto do final do século XX, a mentira almeja destruir a verdade. Consciente das tradições e das discussões clássicas, Vidal-Naquet faz alusão a autores e textos que conformaram o debate na Antiguidade. Assim, o historiador recorda a potencialidade das disposições das musas, que podem mentir, mas também dizer a verdade, e não deixa de lembrar que a história, juntamente com a filosofia, interviu nas contendas ao se distanciar da poesia e declarar seu discurso como um saber que busca a verdade (Vidal-Naquet, 1988, p. 82). A aproximação da história com a filosofia representa, acredito, um passo importante no projeto de Vidal-Naquet. O empreendimento platônico de combate às iniciativas sofísticas parece readquirir, nas décadas finais do século XX, nova vitalidade - se não mesmo uma continuidade - afinal, a antiga sofística passa a ser identificada à mentira moderna. ${ }^{3}$

A sugestão de Vidal-Naquet pode ser explorada neste artigo. Ainda que o historiador francês não faça referência diretamente ao texto "Hípias menor", a obra é parte do esforço platônico de contestação da sofística. Elaborado provavelmente no final do século IV a.C., o diálogo encena uma disputa literária 
entre o filósofo Sócrates e o sofista Hípias a respeito da caracterização e das possíveis semelhanças e diferenças entre os personagens homéricos Ulisses e Aquiles. Para Hípias, Aquiles é “o homem da franqueza e da verdade", enquanto Ulisses representa o "homem das mentiras e dos ardis" (Platão, 1999, p. 66). Contudo, as definições serão progressivamente contestadas por Sócrates, que procura, ainda, demonstrar que a capacidade de enganar decorre não da ignorância, mas, ao contrário, de uma espécie de inteligência. Com isso, se, para Hípias as posições do verdadeiro e do mentiroso são excludentes, para Sócrates, elas revelam-se convergentes - o que permite ao filósofo matizar e mesmo inverter a caracterização inicial. Nas palavras de Sócrates, enfim, "Está visto que o mesmo homem que mente é o que diz a verdade, de tal sorte que Ulisses, se era mentiroso, força é que seja verdadeiro, do mesmo modo que Aquiles, se era verdadeiro, força é que seja mentiroso: os dois homens não diferem entre si [...], antes se assemelham" (Platão, 1999, p. 78). O diálogo platônico aborda, na sequência, outras temáticas a partir do eixo das verdades e mentiras, mas é encerrado de modo aporético, com Sócrates reconhecendo que não poderia concordar com suas próprias conclusões (Platão, 1999, pp. 97-98). Para os fins desse artigo, creio ser válido reter, do argumento socrático, a percepção da dificuldade na tentativa de distinção entre aquele capaz de falar a verdade e aquele que profere a mentira, bem como a tese central do diálogo, que, tal como sugere Maria Teresa Schiappa de Azevedo, seria "a condenação de um saber que não sabe reflectir-se, alimentando-se do ilusório poder de convicção sobre uma assistência, que facilmente confunde realidade e espectáculo" (Platão, 1999, p. 32).

Ora, a referência ao "ilusório poder" e ao "espetáculo" no excerto permite recuperar o diagnóstico de Vidal-Naquet acerca de seu tempo. Para o historiador francês, a experiência negacionista era parte de uma sociedade estruturada em torno da propaganda e do consumo de massas; sociedade essa marcada, portanto, pela mentira e pela fetichização da mercadoria. É nesse espaço que a conduta falsificadora adquire lugar. Ao situar, por exemplo, o método do negacionista Robert Faurisson, o historiador argumenta: “é, em nossa sociedade de encenação e espetáculo, uma tentativa de extermínio no papel, que substitui o extermínio no real. Ressuscitam-se os mortos para atingir melhor os vivos" (Vidal-Naquet, 1988, p. 45). Estamos imersos, assim, em sociedades - a francesa do século do XX, a grega do século IV a.C. - nas quais 
confrontam-se a aparência e a realidade, o saber falso e o saber verdadeiro, o espetáculo baseado na eficácia da palavra e o debate construído pela razão. É significativo, desse modo, que, na abertura de "Hípias menor", Sócrates decida interpelar seu oponente apenas após o fim de sua conferência para um grande público. Enquanto, especula-se, Hípias obtém o reconhecimento entusiasmado dos espectadores presentes, Sócrates permanece calado (Platão, 1999, p. 14). Apenas depois da dispersão do público e da troca de ambiente seria possível, em tese, iniciar uma confrontação de ideias. Mas a expectativa, como sugerido, não se concretiza, pois a discussão se encerra sem conclusões válidas.

O exemplo platônico-socrático inspira o projeto de Vidal-Naquet. Como mencionado, a sofística antiga retorna para identificar a prática negacionista moderna. Daí emerge também uma das primeiras regras do conjunto de procedimentos de combate aos detratores da verdade: a impossibilidade do debate. A ausência de qualquer ponto em comum, de um pressuposto compartilhado, inviabiliza a possibilidade de uma interlocução mínima. Ao referir-se, por exemplo, a Faurisson, Vidal-Naquet argumenta:

Responder como, se a discussão é impossível? Como se procede com um sofista, ou seja, com um homem que parece com aquele que diz a verdade e cujos argumentos devem ser completamente desmontados para desmascarar as mentiras. Tentando também elevar o debate, mostrar que a impostura revisionista não é a única a ornar a cultura contemporânea e que é preciso compreender não somente o como da mentira, mas também o porquê (Vidal-Naquet, 1988, p. 15, grifos meus).

Caracterizar o negacionismo como um exemplo da sofística permite a Vidal-Naquet compreender a falsificação com o recurso a experiências e ferramentas diversas. Faurisson, tal como os personagens homéricos interpretados por Sócrates, é um sujeito que reúne em si a capacidade de proferir mentiras e verdades, mas seu saber é apenas aparente, constitui-se como uma prática esvaziada e ilusória. Nesse sentido, se respostas diretas parecem impossíveis - e Vidal-Naquet lembra que seu adversário jamais tentou contestar diretamente suas próprias refutações -, o historiador também recusa o silêncio completo. Não sem hesitações iniciais, ele acaba por reconhecer a importância de intervir e atuar para delimitar o alcance e a difusão da mentira. Em sua opinião, é necessário não apenas identificar, mas também vigiar e circunscrever os negacionistas (Vidal-Naquet, 1988, p. 210). Ao mesmo tempo, ele refu- 
ta a intervenção judiciária, recordando que a Justiça não é a arena mais apropriada para deliberar sobre a história. Evidentemente, cabem aos tribunais decidir sobre os direitos dos indivíduos, mas jamais sobre o conteúdo histórico (Vidal-Naquet, 1988, p. 210). E isso já aponta para uma diferença importante em relação à busca pela mentira empreendida por Deborah Lipstadt.

Como então proceder? Como desmascarar e combater a mentira difundida pelos projetos que se anunciam como históricos, mas que estão voltados para a falsificação? Vidal-Naquet vale-se de uma série de medidas, que incluem o que ele chama, por exemplo, de uma "geografia do revisionismo", cujo pressuposto é múltiplo: trata-se de investir em um mapeamento das editoras que promovem e fazem circular esse "pseudoconhecimento"; além de identificar os vários gêneros de escrita por meio dos quais atuam os negacionistas, como panfletos, propagandas etc.; e ainda distinguir os países que mais desenvolvem e difundem as mentiras por meios de institutos de pesquisa e financiamento. Essa agenda de atuação, no entanto, não deixa de afetar e deslocar a prática histórica para áreas cinzentas, espaços imprecisos de saber. Ao opor a seita, como denomina, negacionista ao projeto historiográfico, Vidal-Naquet assevera:

Afinal, estamos sendo obrigados, de certa forma, a provar o que aconteceu. Nós que, desde 1945, sabemos, temos de ser demonstrativos, eloquentes, temos de empregar as armas da retórica, entrar no mundo daquilo que os Gregos chamam de Peithô, Persuasão, que transformaram numa deusa que não é nossa. É possível saber realmente o que isso significa? (Vidal-Naquet, 1988, p. 40).

O historiador, então, que inscreveu sua atividade na pesquisa e que, nesse movimento, procurou afastar-se do saber divino, articulado pelas musas, percebe-se modernamente arrastado para o âmbito da retórica, no qual o argumento é avaliado a partir de critérios que são estrangeiros à historiografia. $\mathrm{Na}$ disputa entre saberes, além disso, a retórica, ao menos do ponto de vista platônico, confundia-se com a sofística. Platão é não apenas o responsável por cunhar o termo "retórica", mas também aquele que o separa, segundo Barbara Cassin, da filosofia (Cassin, 2005, pp. 145-146). É certo que o filósofo concebe também um uso adequado do saber retórico, mas, no caso em questão - e na perspectiva de Vidal-Naquet -, a retórica é identificada com a sofística. Teríamos, assim, dois usos da retórica em Platão: uma "retórica sofística", caracterizada pela "adulação que desliza sob a máscara da legislação e sob a da 
justiça"; e uma "retórica filosófica", "a do dialético que analisa e compõe as ideias", e que se confunde, assim, com a "própria filosofia” (Cassin, 2005, pp. 149-150). A divisão entre saberes alternativos empreendida por Platão, entre bons e maus usos do raciocínio para fundamentar e legitimar a filosofia, é retomada por Vidal-Naquet para diferenciar a história do negacionismo. De um lado, temos o conhecimento histórico, organizado a partir da verdade e da prova, de outro, a prática negacionista, que opera mobilizando um saber ilusório e aparente.

Parte da refutação histórica em relação à sofística negacionista é elaborada por meio da construção de um modo de agir retórico - ou, para recorrer à divisão proposta por Cassin, de uma "retórica filosófica". As regras do "método revisionista" são, argumenta Vidal-Naquet, bastante evidentes: "A mentira pura e simples, o falso, o apelo a uma documentação completamente fantástica" (Vidal-Naquet, 1988, p. 40). Identificando seus pressupostos, torna-se possível, então, combatê-los. Uma segunda regra diz respeito à, talvez, principal ferramenta do historiador na construção de seu saber: a prova. Aqui, o procedimento adotado por Vidal-Naquet é triplo: trata-se de, em primeiro lugar, criticar o tratamento negacionista em relação às provas da história; em uma segunda etapa, refutar os indícios ou os procedimentos negacionistas adotados como comprovação das suas teses ilusórias; e, por fim, reafirmar e reassegurar os métodos e as provas já consolidadas no trabalho historiográfico. Priorizo, neste artigo, esse terceiro aspecto.

Preocupado com a "qualidade" da prova, o historiador reitera o valor da documentação, analisada e legitimada de maneira minuciosa ao longo dos textos, e mobiliza um dos primeiros procedimentos desenvolvidos pela escrita histórica como forma de atestação: a autópsia. Reconhecida e valorizada na Antiguidade por Tucídides, a visão direta aparece no projeto de Vidal-Naquet como uma ferramenta fundamental para comprovar o saber produzido. Além disso, ao mencionar as práticas negacionistas, Vidal-Naquet afirma que a estratégia utilizada envolve justamente rejeitar os testemunhos diretos e aceitar como legítimos os testemunhos daqueles que nada viram (Vidal-Naquet, 1988, p. 81). Conduta análoga será adotada pelo adversário de Lipstadt. Assim, o que se verifica é que a mesma prática parece ser empregada tanto pelos negacionistas quanto na refutação destes por Vidal-Naquet - o que apenas corrobora a importância atribuída ao procedimento autopsial. A epistemologia baseada 
na visão direta, fundamental para a construção da verdade na historiografia antiga, se mantém ativa na contemporaneidade.

Um ponto relevante, já destacado por Guido Schepens, diz respeito, contudo, às diferenças entre a autópsia antiga e moderna. Para o historiador italiano, enquanto os antigos visualizavam os fatos, os modernos, já distanciados dos eventos que narram, procuram, antes, visualizar as fontes (Schepens, 1980, p. 4). Nesse sentido, além de identificar, quando possível, testemunhos que viram os documentos e, portanto, são considerados mais autorizados, o próprio Vidal-Naquet reiteradamente atesta que "tem sob os olhos" determinadas fontes que asseguram a veracidade do que afirma. Desse modo, após discorrer sobre o "método revisionista" e reproduzir parte de suas conclusões improcedentes e absurdas, o historiador francês preocupa-se em assegurar a origem de suas próprias afirmações: "Recorrendo às fontes, todos poderão constatar que não estou inventando". E, na sequência, confirma que tem, "diante dos olhos", uma revista com os autos de um evento negacionista (Vidal-Naquet, 1988, pp. 38-39). A autópsia moderna não serve apenas para comprovar a verdade, mas também para desautorizar a contrafação. Após citar outros exemplos de falsificação, o historiador intervém: "É mentira. Tenho diante dos olhos a tradução de uma investigação feita em Cracóvia em junho de 1945 sobre os orifícios de ventilação da câmara de gás de Birkenau [...].” (Vidal-Naquet, 1988, p. 40, nota 42 , grifo meu). ${ }^{4}$

O testemunho de Vidal-Naquet, contudo, transcende sua própria visão. Ele fala não apenas como um historiador, mas como um filho que perdeu os pais nos campos de concentração nazistas. Segundo Paul Ricoeur, existe, no relato de Vidal-Naquet, uma dimensão dupla que combina atestação incontestável e protesto moral (Ricoeur, 2007, p. 271). Aliás, frente aos acontecimentos "limites", como é o caso do Holocausto, a tarefa do historiador é já diferente: não se restringe mais "à habitual caça à falsificação", mas comporta ainda a "discriminação dos testemunhos em função de sua origem", ou seja, a análise e a diferenciação dos relatos de sobreviventes, de perpetradores, de espectadores envolvidos etc. (Ricoeur, 2007, p. 271). A percepção das transformações e das qualificações do papel da testemunha reforçam as diferenças entre as versões antiga e moderna da autópsia. Por razões como essas - e, como bem sintetiza Hartog -, Vidal-Naquet poderia ser caracterizado como histor, aquele que intercede e é chamado a testemunhar, ainda que um dos lados o 
seja apenas em aparência (Hartog, 2007). Afinal, os negacionistas não fazem história, mas falsificam a historiografia e o próprio passado, como define Moraes. Os negacionistas, enfim, realizam um saber aparente, ilusório - fazem, no máximo, um pastiche da história (Vidal-Naquet, 1988, p. 178).

\section{História E Direito: Como (NÃo) SE DEVE ESCREVER A História}

A “anatomia da mentira” realizada por Vidal-Naquet é mencionada no livro da historiadora norte-americana Deborah Lipstadt, Denying the Holocaust: The Growing Assault on Truth and Memory, publicado originalmente em 1993 (Lipstadt, 1994, p. 9). Preocupada com a disseminação de versões mentirosas em relação ao Holocausto, Lipstadt procurou mapear as tentativas de falsificação da prática historiográfica. Ao atribuir nomes e identificar os negacionistas, como Faurisson, David Irving e tantos outros, tornou-se alvo de uma batalha jurídica, travada no final da década de 1990 e no início dos anos 2000, que a acusava de difamação. O caso, de extrema importância, oferece um segundo exemplo de busca pela mentira. Os dois empreendimentos, é certo, guardam semelhanças, na medida em que ensejam reflexões sobre os pressupostos da prática historiográfica, sobre os requisitos que definem a pesquisa e sobre os fundamentos do saber histórico. No entanto, o exemplo de língua inglesa oferece aqui novos desdobramentos, pois permite recuperar um debate travado na arena jurídica e que conta com repercussões mais vastas, tendo sido objeto de livros diversos, de vídeos e mesmo de uma produção cinematográfica com um orçamento na casa dos dez milhões de dólares. ${ }^{5}$ Temos aqui um debate historiográfico que se torna público e que ultrapassa, em muito, a querela acadêmica ou especializada.

Em Denying the Holocaust ["Negando o Holocausto", em tradução livre], o opositor de Lipstadt é apresentado como alguém que distorce indícios, manipula documentos e altera dados, de modo a sustentar a inexistência do Holocausto. Por isso, ele pode ser considerado um dos porta-vozes mais perigosos do negacionismo (Lipstadt, 1994, p. 182). A caracterização de negacionista o levou a instaurar um processo, na Grã-Bretanha, contra a historiadora e a sua editora. O detalhe relevante da situação é que, nesse caso, o ônus da prova deve recair sobre a autora do livro. Conforme sintetiza Lipstadt em Negação: "O sistema jurídico britânico colocava o ônus da prova em minhas mãos, como 
ré. Era uma imagem espelhada da lei americana: nos Estados Unidos, Irving teria de provar que eu menti; no Reino Unido, cabia a mim provar que estava dizendo a verdade" (Lipstadt, 2017, p. 18).

Sintética, a afirmação não deixa de ser significativa. Temos um jogo de contrastes e oposições: Estados Unidos e Reino Unido, a ré que precisa provar, a disputa entre mentira e verdade. Nessas circunstâncias, cabe à historiadora atestar a verdade da sua afirmação - afirmação essa que sugere a mentira do seu oponente e, por extensão, a impossibilidade de concebê-lo como historiador. Além disso, o debate aqui precisa respeitar regras próprias - distintas daquelas que costumam orientar a prática acadêmica. Tal como Vidal-Naquet, Lipstadt não considerava o tribunal o lugar mais apropriado para dirimir questões históricas. Se os historiadores não são juízes, a História e a Justiça operam de modos diversos:

Ademais, eu não acreditava que os tribunais fossem o espaço ideal para investigações históricas. Os negacionistas, eu afirmava, deveriam ser contidos com pesquisas razoáveis, e não com o peso da lei. Parecia-me que os tribunais faziam justiça estimulando as partes a apresentar o que consideram provas convincentes, como provas físicas e fatos concretos, com o objetivo de convencer um júri ou um juiz além de um ônus da prova. Os historiadores tentam estabelecer a "verdade" histórica determinando objetivamente o que aconteceu; consideram o contexto e as circunstâncias de um dado acontecimento ou documento; interpretam indícios e apresentam suas opiniões, sempre cientes de que outros historiadores podem olhar para o mesmo material e, sem serem vítimas de qualquer engano, chegar a conclusões distintas. Os historiadores também sabem que, conforme novas fontes de documentos surgem, algumas "verdades" podem ficar ultrapassadas. Sucintamente: as verdades históricas não podem ser medidas como a poluição do ar de uma cidade (Lipstadt, 2017, p. 19).

No entanto, como acusada, a historiadora não poderia ignorar ou mesmo recusar o debate. A dimensão pública aqui escapa à intencionalidade da agenda de historiadores e historiadoras. Isso, por sua vez, impõe um desdobramento que não pode ser negligenciado: se a verdade da história é diferente da verdade da justiça, o desfecho jurídico é válido igualmente para o campo histórico? Dito de outro modo: se o resultado do julgamento comprova a mentira do negacionista, em que medida essa verdade pode ser aceita pela história? ${ }^{6}$ Em um exercício análogo ao que foi elaborado por Vidal-Naquet na 
sua "geografia do revisionismo", Lipstadt procura identificar as táticas mobilizadas pelos falsificadores. Ainda que conteste o saber acadêmico, o pseudoconhecimento busca emular sua forma de produção (Kleinberg, 2019, p. 4). Assim, o negacionismo como prática organiza-se ao redor de instituições de pesquisa, eventos acadêmicos, obras e materiais de divulgação, ou seja, se apresenta como um saber que se parece com o conhecimento histórico, embora não o seja de fato. As estratégias empregadas pelos falsificadores, todavia, como seria possível esperar, são praticadas com diferentes níveis de "qualidade”. Negacionistas como o adversário de Lipstadt são falsificadores sofisticados. Seja por possuir uma formação como historiador, ainda que incompleta, seja por ter adquirido renome e autoridade em relação à temática da II Guerra Mundial, David Irving era capaz de, segundo Lipstadt, "plantar sementes de verdadeira confusão acerca do fato" (Lipstadt, 2017, p. 51). A afirmação é relevante. Aqui, a simples oposição entre verdade e mentira parece se desfazer. Temos uma mentira que se apresenta com as roupas da verdade, uma mentira que se constrói de modo a emular o conhecimento acadêmico e que se vale da autoridade e do prestígio de quem a profere. A constatação permite recuperar a analogia realizada por Vidal-Naquet entre o negacionismo e a sofística. Tal como o Sócrates platônico havia sugerido, muitas vezes é o conhecedor de uma temática aquele mais capaz de produzir o discurso mentiroso. É justamente o saber adquirido na prática da historiografia que permite a Irving produzir, de modo deliberado e sofisticado, a falsificação.

Como, então, investigar a mentira especializada? A estratégia adotada pela equipe de Lipstadt foi comprovar não propriamente o evento, na medida em que sua ocorrência não poderia ser questionada, mas a verdade de suas afirmações prévias, ou seja, a verdade da mentira de seu opositor. Nas palavras de Lispstadt: "Como nosso objetivo não consistia em provar que o Holocausto havia acontecido, e sim que aquilo que eu escrevera sobre Irving era verdadeiro, pedimos aos especialistas para reunirem provas que um historiador justo e objetivo usaria para chegar a conclusões sobre o Holocausto." (Lipstadt, 2017, p. 70). Assim, a tática consistia em avaliar e qualificar os escritos do adversário, buscando seus desvios. Por sua vez, isso implicava determinar igualmente o que pode ser concebido como uma prática adequada e justa da história e o que a história não deve ser, como ela não deve ser escrita. A formação incompleta de seu oponente o qualifica para ser um historiador? Sua 
prática corrompida ou equívoca, ao contrário, impossibilita a atribuição do título? Para Lipstadt, leitora das obras de seu opositor, ele jamais poderia ser classificado como historiador. Desse modo, na abertura dos trabalhos do processo, o advogado Richard Rampton buscou delimitar o mote do julgamento: "Vossa Excelência, o senhor Irving define a si mesmo como historiador. A verdade, porém, é que ele não é um historiador, mas um falsificador da história. Para colocar de forma mais direta, ele é um mentiroso". E, na sequência da sua fala, ele acrescentou: "Esse processo [...] não era sobre versões concorrentes da história, mas sobre verdades e mentiras." (Lipstadt, 2017, p. 121).

Essa posição, contudo, não era compartilhada por toda a comunidade acadêmica. Richard Evans, historiador especialista em história alemã, foi convocado pelo tribunal para elaborar um parecer independente sobre o caso. Sua postura, ao menos no princípio, era diferente. Incumbido de realizar a análise da obra do negacionista, inicialmente o historiador britânico descartou a ideia sobre a adequação ou inadequação da caracterização de historiador ao negacionista. Segundo recorda Lipstadt, Evans teria dito: “É um debate semântico absurdo declarar que alguém que escreveu duas dezenas de livros sobre história não seja historiador. Nenhum júri aceitaria isso." (Lipstadt, 2017, p. 75).

No entanto, como dito, a estratégia adotada ao longo do julgamento foi essa. Nesse sentido, o processo parece incidir tanto sobre "verdades e mentiras", quanto sobre o ofício historiográfico. O próprio negacionista procurou propalar suas credenciais de historiador e defender o "rigor histórico" de seu emprego de documentos, indícios e dados, ao mesmo tempo em que, tomando de empréstimo o verniz acadêmico, criticava outros historiadores e os classificava como indolentes e incorrigíveis (Lipstadt, 2017, pp. 130-131). A questão foi, inclusive, colocada diretamente ao negacionista: "Qual é a sua tarefa como historiador, senhor Irving? [...] Não seria apresentar uma interpretação objetiva e justa do efeito cumulativo de todos os indícios?" (Lipstadt, 2017, pp. 159-160). Acuado, Irving tentou invalidar o parecer emitido por Evans, alegando que não existiam padrões objetivos para a definição do papel do historiador. A recusa do juiz à solicitação permitiu que a pesquisa de Evans fosse incorporada. Seu posicionamento, após entrar em contato com várias obras do negacionista, mudou radicalmente. É válido recuperar suas conclusões, depois transformadas em livro: 
Mas se entendermos por historiador alguém que está preocupado em descobrir a verdade sobre o passado e em oferecer uma representação tão precisa quanto possível, então Irving não é um historiador. Aqueles que sabem, de fato, estão acostumados a evitar o termo quando se referem a ele e usam, em vez disso, alguns circunlóquios como escritor histórico. Irving é essencialmente um ideólogo que usa a história para seus próprios objetivos políticos; ele não está preocupado sobretudo em descobrir e interpretar o que aconteceu no passado, ele está preocupado apenas em oferecer um relato seletivo e tendencioso disso para promover seus próprios fins ideológicos no presente. A principal preocupação do verdadeiro historiador, no entanto, é com o passado. É por isso que, em minha opinião, Irving não é um historiador (Evans, 2001, p. 251, tradução minha). ${ }^{7}$

O longo excerto permite sugerir alguns desdobramentos. Evans define o que caracteriza a boa prática e assim prescreve como a história deve ser escrita. É também na condição de historiador profissional que ele denega o "saber" de Irving, ao sugerir que o principal objetivo da historiografia deve sempre ser o passado. No entanto, seu parecer, construído a partir de uma análise rigorosa da produção do negacionista, não está, por sua vez, submetido exclusivamente aos fatos pretéritos, na medida em que suas repercussões ultrapassam o próprio caso e impactam o fazer historiográfico como um todo, ou seja, incidem também sobre o presente da disciplina. Dito de outro modo: é como historiador que Evans analisa o conteúdo produzido por Irving, mas seu parecer ultrapassa o âmbito da historiografia, pois concerne à prática na sua integralidade.

Essa ampliação em relação ao escopo original, o passado, aparece também na forma e na linguagem empregadas no parecer. Segundo Evans, há diferenças significativas, por exemplo, entre a pesquisa elaborada para o julgamento e o livro publicado posteriormente (Evans, 2001, pp. XI-XII). Esse aspecto acentua a separação entre o discurso historiográfico e o discurso jurídico e, nesse sentido, a incompatibilidade entre a História e o sistema judiciário. De modo análogo, por determinação da equipe jurídica, Lipstadt não deu entrevistas e nem testemunhou no tribunal durante todo o julgamento (Lipstadt, 2017, p. 20). Ora, a adequação do discurso ao público constitui um dos princípios básicos da "Retórica" aristotélica (Aristóteles, 1998, Livro II). Isso permite recuperar a sugestão de Vidal-Naquet: na busca pela mentira, os historiadores se veem obrigados a ingressar em zonas imprecisas, reguladas por 
critérios estranhos, como a persuasão e a retórica. Se o tribunal não é, como sugerem Vidal-Naquet e Lipstadt, o espaço ideal para dirimir questões históricas e se o discurso aí produzido se organiza a partir de pressupostos diferentes, em que medida o resultado obtido em uma área pode ser transferido para outra? A verdade construída pela historiografia tem legitimidade no campo jurídico?

As práticas jurídica e historiográfica possuem assim orientações diferentes. Mas, é possível dizer: também há pontos de contato entre ambas. Um dos pressupostos centrais da tarefa do historiador, como já aludido por Vidal-Naquet, continua a ser a visão direta. O procedimento, contudo, não é exclusivo da historiografia. Também a equipe jurídica optou, para a construção da estratégia, por uma visita aos campos de concentração e extermínio: era necessário ver o local (Lipstadt, 2017, p. 86). Se a necessidade da visão direta reaproxima as duas práticas, é importante destacar também as diferenças: como salientado, a comprovação moderna é construída pela observação das fontes, enquanto a versão antiga ocupava-se com a visão dos eventos ou locais. Assim, a autópsia jurídica parece estar mais próxima do modelo antigo de visualização. Irving, na sua tentativa de simular o conhecimento histórico, também faz uso do procedimento. Seu emprego, porém, não deixa de ser invertido, na medida em que procurava justamente refutar as testemunhas oculares que afirmavam ter visto as câmaras de gás (Lipstadt, 2017, p. 195). Irving assim - para recuperar a proposta de Moraes citada acima - falsifica a historiografia e o passado.

As disputas pela visão que autoriza o conhecimento histórico adquirem diferentes formas. Isso porque a dimensão visual como um elemento de comprovação não se resume à visão de testemunhas. É possível pensar na estratégia de uma autópsia vicária, ou seja, indireta, estimulada pela incorporação de imagens e fotografias nos livros. Na avaliação que teceu sobre a obra do negacionista, como parte do julgamento, Evans destacou seu uso desequilibrado de imagens como uma forma de equivaler às ações nazistas aos crimes praticados pelos aliados. Em uma de suas principais obras, as fotografias e as legendas faziam alusão apenas às vítimas dos bombardeios aliados e não havia nenhuma representação gráfica das vítimas dos campos de extermínio (Lipstadt, 2017, p. 271).

Esses são apenas alguns dos indícios, arrolados no trabalho da equipe, que visaram buscar a mentira do negacionista. Seria possível mencionar também 
as dificuldades impostas de modo deliberado ao processo de checagem das fontes e dos documentos - citados e apresentados de modo pouco coerente -, e também a presença de equívocos propositais na tradução e na citação de determinados termos e expressões na documentação oficial alemã. Ao final do trabalho, a equipe apresentou mais de trinta exemplos de, para recorrer ao termo de Lipstadt, "malversações históricas". Mais do que possíveis erros involuntários, as falsificações encontradas indicavam um padrão na medida em que convergiam para fins específicos: "absolver Hitler e negar o Holocausto" (Lipstadt, 2017, p. 331).

A partir disso, a conclusão só poderia ser uma - e retomava, nas considerações finais, o mote que havia inaugurado o julgamento: "O senhor Irving é um mentiroso” (Lipstadt, 2017, p. 332). Para fundamentar essa conclusão, a equipe foi capaz de constatar as posições políticas e ideológicas que embasavam a pseudo-história do negacionista. Mais uma vez, esse aspecto permite recuperar a sugestão de Vidal-Naquet de que é preciso desvelar o como e o porquê das mentiras. Na transcrição das falas do processo, o advogado Rampton argumentava:

Até que ponto [...] o antissemitismo do [...] senhor Irving é causa da apologia a Hitler ou vice-versa, isso não é importante. [...] [Esse antissemitismo] levou-o a degradar sua reputação como um historiador sério - o mais espúrio possível, como agora podemos ver - com o objetivo de, falsamente, absolver Hitler e disseminar propaganda antissemita violenta (Lipstadt, 2017, p. 334).

O parecer final, emitido pelo juiz do processo, recupera aspectos importantes para o presente texto. Ainda que classificasse Irving como um "historiador militar", Charles Gray concordava com os pontos levantados e assinalava as inúmeras tentativas de falsificação identificadas. Recuperando o mote que orientou o julgamento, o juiz então conclui afirmando que o trabalho do negacionista está distante do que se espera de um historiador responsável, objetivo e justo (Lipstadt, 2017, p. 351). Desse modo, o adversário de Lipstadt pode ser agora chamado de negacionista ou mesmo de romancista - rótulo atribuído por sua própria editora, após polêmica na década de 1980 em relação ao número de mortos dos bombardeiros em Dresden (Lipstadt, 2017, p. 230). O "absurdo debate semântico", tal como sugerido por Evans, tornou-se, enfim, possível. Não sendo mais um historiador, Irving não passa agora de um mentiroso. 
Afirmar que os negacionistas não são historiadores é suficiente para combater a mentira? Rotular suas obras como romances ou suas práticas como exemplos de sofística ou retórica encerra a discussão? As caracterizações e denominações parecem insuficientes frente ao desafio imposto pela conduta negacionista, na medida em que parecem ser apenas medidas reativas, posteriores à disseminação da malversação e da falsificação. Sem qualquer pretensão de oferecer soluções definitivas, é possível ensaiar, no entanto, algumas conclusões a partir das duas tentativas de busca pela mentira.

Vidal-Naquet, ao mesmo tempo em que empreende uma longa luta contra os negacionistas, parece reconhecer que nenhuma demonstração é capaz de convencer a todos. Como mencionado acima, diante de uma "mentira total", na qual a "conclusão precede as provas", a refutação se apresenta como impossível. Desse modo, embora tenha elaborado uma "anatomia da mentira", reiterando as ferramentas do discurso histórico (como a consulta aos documentos, o valor das testemunhas e da autópsia), o historiador francês parece reconhecer a insuficiência da história. Daí a impossibilidade de debater e confrontar diretamente a mentira. As amostras aqui são, forçosamente, redutoras. No entanto, uma percepção que pode ser extraída do exemplo é que, a despeito dos avanços da erudição e das técnicas de atestação, o saber histórico ainda enfrenta a falsificação com alguns dos instrumentos criados na Antiguidade, ou seja, com armas elaboradas em um contexto no qual a mentira não buscava, tal como identificou Arendt, eliminar a verdade. A constatação, todavia, não deve levar à descrença ou à inação. Ao contrário, Vidal-Naquet decide justamente utilizar as ferramentas da história e o seu amplo conhecimento sobre a Antiguidade na luta contra a mentira. Seu empreendimento, assim, talvez possa ser utilizado como um modelo. O historiador recupera o projeto platônico que opunha o saber real filosófico aos saberes aparentes da retórica e da sofística. A iniciativa permite, por um lado, alargar o histórico da oposição entre verdade e mentira, remontando-o ao mundo antigo e, por outro, possibilita reunir novos aliados e instrumentos para a confrontação. A história, de modo algum, está isolada nessa contenda: ela pode contar com o subsídio da filosofia na sua tentativa não apenas de mapear e circunscrever a falsificação, mas também de compreender, de modo mais preciso e detalhado, o fenômeno negacionista. Se, como sugere Sócrates, o indivíduo que sabe é aquele mais capaz de mentir, esse mesmo indivíduo também pode ser 
o mais apto para reconhecer e descortinar a mentira. Assim, os ecos do debate antigo sobre a verdade e a mentira permanecem presentes e atuantes na disputa contemporânea.

Por sua vez, o alcance do julgamento da historiadora norte-americana e as repercussões daí advindas parecem sugerir um interesse público por temáticas relacionadas ao passado. Aqui, contudo, creio ser mais adequado falar não tanto de uma história pública - ainda que essa dimensão não esteja ausente -, mas de uma história que se torna pública, se publiciza a partir da atração, do consumo do tema. Nesse sentido, a mesma sociedade do espetáculo que possibilita, para Vidal-Naquet, a difusão das mentiras, parece garantir, paradoxalmente, a audiência às querelas e aos julgamentos concernentes aos conteúdos históricos. Como objeto de disputas, a história judicializada autoriza e veta discursos, mas não impede sua disseminação, ainda mais quando essas narrativas emulam o saber acadêmico, organizando-se a partir de eventos, revistas e materiais de divulgação. Nesses casos, a conduta negacionista imita a prática histórica de modo a produzir um discurso supostamente legítimo, mas que se revela apenas um saber aparente, ilusório, desprovido de fundamentação. A busca de Lipstadt também pode oferecer, acredito, sugestões significativas de atuação. Se Vidal-Naquet evocou o projeto platônico e recorreu à filosofia, Lipstadt, de modo análogo, reafirmou o valor da verdade com a participação de especialistas de diferentes áreas: historiadores, promotores, pesquisadores, cientistas políticos, cineastas etc. Enfim, o que emerge da sua busca pela mentira é o caráter coletivo e colaborativo do seu empreendimento: a soma possível dos saberes das ciências humanas e jurídicas que possuem procedimentos afins, como a autópsia, e contrastantes, como a persuasão e a retórica.

Hannah Arendt, nas suas reflexões sobre a temática, deixava transparecer um otimismo em função da insustentabilidade da mentira a longo prazo. Para isso, apoiava-se, sobretudo, na força de duas instituições, caracterizadas como "refúgios da verdade", que serviriam de anteparo à mentira: o sistema judiciário e a universidade (Arendt, 2016, pp. 321-322). Ambas estiveram presentes no caso de Lipstadt, mas não custa lembrar que Faurisson, o opositor de Vidal-Naquet, mentia enquanto professor e integrante do sistema universitário francês. ${ }^{8}$ De qualquer forma, a resposta à questão concernente à força da prática histórica frente ao poder da mentira e da falsificação pode incluir o vigor e a saúde atual das universidades e da justiça. Creio não ser excessivo falar em 
saúde. Naquele que talvez seja um dos principais textos voltados para a relação dupla e ambígua entre história e falsificação, Grafton, em Forgers and critics ["Falsários e críticos", em tradução livre] argumenta que a relação é incontornável, ou seja, a história e a falsificação estarão continuamente face a face, em diálogo ou em confronto. No entanto, Grafton também alerta: "O exercício da crítica é um sinal da saúde e da virtude em uma cultura; a predominância da falsificação é um sinal da doença e do vício" (Grafton, 1990, p. 127, tradução minha). ${ }^{9}$ Diante de uma balança na qual a ênfase atual parece recair para o polo da falsificação, estaríamos hoje - e talvez seja útil perguntar em um contexto pandêmico - mais capacitados, não para a anatomia de uma mentira, mas para uma necrópsia da verdade?

\section{REFERÊNCIAS}

ARAUJO, Valdei de; VALIM, Patricia; AVELAR, Alexandre. Revista Brasileira de História: Dossiê Negacionismos e os usos da história. 7 out. 2020 (97 min. 34 seg.). Disponível em: https://www.youtube.com/watch?v=VMG-XHoIsLc\&ab_ channel=ANPUH-Brasil. Acesso em: 30 nov. 2020.

ARENDT, Hannah. Entre o passado e o futuro. São Paulo: Editora Perspectiva, 2016. ARISTÓTELES. Retórica. Lisboa: Imprensa Nacional - Casa da Moeda, 1998.

CASSIN, Barbara. O efeito sofístico: Sofística, filosofia, retórica, literatura. Tradução de Ana Lúcia de Oliveira; Maria Cristina Franco Ferraz; Paulo Pinheiro. São Paulo: Editora 34, 2005.

EVANS, Richard. Lying about Hitler: History, Holocaust and The David Irving Trial. New York: Basic Books, 2001.

GINZBURG, Carlo. El juez y el historiador: consideraciones al margen del proceso Sofri. Madrid: Anaya \& Mario Muchnik, 1991.

GRAFTON, Anthony. Forgers and Critics: Creativity and Duplicity in Western Scholarship. London: Collins \& Brown Limited, 1990.

HARTOG, François. Vidal-Naquet, historien en personne: l'homme-mémoire et le moment-mémoire. Paris: La Découverte, 2007.

HOLOCAUST DENIAL ON Trial. Disponível em: https://www.hdot.org/. Acesso em: 26 nov. 2020.

IRVING V PENGUIN Books Ltd. Disponível em: https://en.wikipedia.org/wiki/ Irving_v_Penguin_Books_Ltd. Acesso em: 26 nov. 2020.

KAKUTANI, Michiko. A morte da verdade. Tradução de André Czarnobai e Marcela Duarte. Rio de Janeiro: Intrínseca, 2018. 
KLEINBERG, Ethan. Pandering to the timid: the truth about post truth. Wild On Collective. 2019. Disponível em: https://www.academia.edu/38283250/Pandering to_the_Timid_the_truth_about_post_truth. Acesso em: 30 nov. 2020 .

KOYRÉ, Alexandre. A função política da mentira moderna. Tradução de Andréa Bieri. Anamorfose: Revista de Estudos Modernos, v. III, n. 1, pp. 71-86, 2015.

LIPSTADT, Deborah E. Denying the Holocaust: The Growing Assault on Truth and Memory. New York: Plume, 1994.

LIPSTADT, Deborah E. Negação: Uma história real. Tradução de Mauricio Tamboni. São Paulo: Universo dos Livros, 2017.

MENESES, Sônia; BAUER, Caroline S.; BARBOSA, Ana Carolina. Episódio 3: Negacionismo e Pós-verdade: impactos sociais e enfrentamento. Podcast produzido por Humanas: Pesquisadoras em Rede. 11 jun. 2020 (38 min. 45 seg.). Disponível em: https://www.humanasrede.com/podcast. Acesso em: 30 nov. 2020.

MORAES, Luís Edmundo de Souza. O Negacionismo e o problema da legitimidade da escrita sobre o passado. SIMPÓSIO NACIONAL DE HISTÓRIA, XXVI, 2011, São Paulo. Anais do XXVI Simpósio Nacional de História, São Paulo, julho, 2011, pp. 1-16.

ORWELL, George. Sobre a verdade. Tradução de Claudio Alves Marcondes. São Paulo: Companhia das Letras, 2020.

PLATÃO. Hípias menor. Tradução de Maria Teresa Schiappa de Azevedo. Lisboa: Edições 70, 1999.

RICOEUR, Paul. A memória, a história, o esquecimento. Campinas, SP: Editora da Unicamp, 2007.

SCHEPENS, Guido. L'autopsie comme problème méthodologique de l'historiographie. In: L'Autopsie dans la méthode des historiens grecs du Vème siècle avant J.-C. Brussels: Koninklijke Academie, 1980. pp. 1-32.

VIDAL-NAQUET, Pierre. Os assassinos da memória: um Eichmann de papel e outros ensaios sobre o revisionismo. Tradução de Marina Appenzeller. Campinas, SP: Papirus, 1988.

VIDAL-NAQUET, Pierre. Les assassins de la mémoire: "Un Eichmann de papier" et autres essais sur le révisionnism. Édition revue et augmentée. Paris: La Découverte, 2005.

\section{NOTAS}

${ }^{1}$ Kakutani sugere que essa situação decorre das perspectivas pós-modernas que foram difundidas por autores como Jacques Derrida e Paul de Man. Ethan Kleinberg, contudo, discorda veementemente desse tipo de associação entre as prerrogativas do pós-modernismo e a corrosão da verdade. Nas suas palavras: "Revisionistas, negacionistas, negacionistas 
climáticos [...] não são e não querem ser considerados pós-modernistas, construcionistas ou desconstrucionistas. Eles querem ser considerados 'realistas'." (Kleinberg, 2019, p. 3). A identificação apropriada do diagnóstico permite confrontá-los. Kleinberg sugere: "No atual momento, precisamos ter em conta a representação pós-moderna dos fatos e da verdade como socialmente construída, a fim de defender a importância desses fatos e o valor deste modo de investigação" (Kleinberg, 2019, p. 4). Originalmente: "Revisionists, negationists, climate-change deniers [...] are not and do not want to be considered postmodernists, constructionists, or deconstructionists. They want to be considered 'realists'." 'In our current moment we need to take heed of the postmodern depiction of facts and truth as socially constructed in order to argue for the importance of these facts and the value of this mode of investigation".

${ }^{2} \mathrm{Na}$ obra de Vidal-Naquet ainda não se verifica a preocupação, hoje corrente, de diferenciar o revisionismo do negacionismo. Se concebido como fraude, como sugerido acima, o negacionismo evidentemente não pode ser aproximado da conduta revisionista. Essa é também a proposta que emerge do diálogo entre as historiadoras Sônia Meneses e Caroline Bauer, no qual o negacionismo é caracterizado como uma prática que inviabiliza os protocolos científicos ou mesmo os recusa (Meneses; Bauer; Barbosa, 2020). Desse modo, procurei manter a equivalência entre revisionismo e negacionismo apenas nas citações da obra de Vidal-Naquet.

${ }^{3} \mathrm{~A}$ continuidade é tributária da própria leitura crítica de Platão em relação à sofística que a distingue da filosofia, leitura esta à qual Vidal-Naquet adere. Ainda que triunfante, essa divisão não é consensual. A partir da primeira metade do século XX, a sofística passou por processos de reabilitação que procuraram atestar, legitimamente, seu papel filosófico. A questão será retomada abaixo. Em "O efeito sofístico", de qualquer forma, Barbara Cassin não apenas discorre sobre as reabilitações, mas também participa dessa releitura da sofística (Cassin, 2005).

${ }^{4}$ Como sugerido, Vidal-Naquet recorre com regularidade ao expediente da autópsia documental. Para outros exemplos, cf. Vidal-Naquet, 1988, p. 46; p. 92, nota 119; p. 177, nota 61. A tradução brasileira da obra optou, em alguns casos, pela versão "diante de mim", enquanto no texto original o procedimento é mobilizado a partir da expressão "sous les yeux", cf. Vidal-Naquet, 2005, p. 33; p. 35, nota 42; p. 40; p. 80, nota 119; p. 114, nota 41; p. 154 , nota 62.

${ }^{5}$ Para acompanhar parte das repercussões do julgamento, bem como o material audiovisual que foi produzido sobre o evento, cf. Irving V Penguin... e Holocaust Denial on...

${ }^{6}$ As relações entre história e o campo jurídico são, evidentemente, complexas. Carlo Ginzburg procurou refletir sobre as proximidades e as diferenças entre as ocupações do historiador e do juiz, na medida em que ambos operam por meio de indícios, provas e testemunhos (Ginzburg, 1991, p. 10). Se existe uma semelhança entre as práticas, baseada na possibilidade de se provar algo de acordo com determinadas regras (Ginzburg, 1991, p. 104), Ginzburg enfatiza as suas divergências, ao salientar, por exemplo, o tratamento diverso desenvolvido em relação ao contexto (Ginzburg, 1991, p. 111). Desse modo, o histo- 
riador italiano, tal como Lipstadt e Vidal-Naquet, critica a indistinção entre os saberes histórico e jurídico e mesmo condena não só a tentativa de redução da categoria do historiador à de juiz, mas também o inverso, a redução do juiz ao papel de historiador (Ginzburg, 1991, p. 112).

${ }^{7}$ No original: "But if we mean by historian someone who is concerned to discover the truth about the past, and to give as accurate a representation of it as possible, then Irving is not a historian. Those in the know, indeed, are accustomed to avoid the term altogether when referring to him and use some circumlocution such as historical writer instead. Irving is essentially an ideologue who uses history for his own political purposes; he is not primarily concerned with discovering and interpreting what happened in the past, he is concerned merely to give a selective and tendentious account of it to further his own ideological ends in the present. The true historian's primary concern, however, is with the past. That is why, in my view, Irving is not a historian".

${ }^{8}$ Vidal-Naquet, no prefácio escrito para uma nova edição de seu livro, reforça a presença dos negacionistas no sistema universitário francês (Vidal-Naquet, 2005, p. II).

${ }^{9}$ No original: "The exercise of criticism is a sign of health and virtue in a civilization; the prevalence of forgery is a sign of illness and vice".

Artigo submetido em 15 de dezembro de 2020.

Aprovado em 9 de março de 2021.

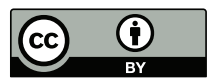

